\title{
HHV8-Negative Primary Effusion Lymphoma of B-Cell Lineage: Two Cases and a Comprehensive Review of the Literature
}

\author{
Neeraj Saini, ${ }^{1}$ Ephraim P. Hochberg, ${ }^{2,3}$ Erica A. Linden, ${ }^{1,3}$ Smita Jha, \\ Heinz K. Grohs, ${ }^{4}$ and Aliyah R. Sohani ${ }^{5}$ \\ ${ }^{1}$ Department of Internal Medicine, North Shore Medical Center, Salem, MA 01970, USA \\ ${ }^{2}$ Center for Lymphoma, MGH Cancer Center, Massachusetts General Hospital, Boston, MA 02114, USA \\ ${ }^{3}$ Department of Medicine, Harvard Medical School, Boston, MA 02115, USA \\ ${ }^{4}$ Department of Pathology, North Shore Medical Center, Salem, MA 01970, USA \\ ${ }^{5}$ Department of Pathology, Massachusetts General Hospital and Harvard Medical School, Boston, MA 02114, USA
}

Correspondence should be addressed to Neeraj Saini; nsaini@partners.org

Received 18 November 2012; Accepted 11 December 2012

Academic Editors: K. Aogi and Y. Niibe

Copyright (c) 2013 Neeraj Saini et al. This is an open access article distributed under the Creative Commons Attribution License, which permits unrestricted use, distribution, and reproduction in any medium, provided the original work is properly cited.

Primary effusion lymphoma (PEL) is a rare extranodal lymphoma that typically presents in a body cavity in the absence of a detectable tumor mass and that occurs predominantly in immunosuppressed individuals. The neoplastic lymphoid cells are frequently infected with human herpes virus 8 (HHV8), also known as Kaposi sarcoma herpes virus (KSHV). We describe two HIV-negative patients who presented with primary effusion lymphoma of B-cell lineage involving the pleural cavity, but whose tumor cells lacked infection by HHV8. We review the English language literature of HHV8-negative PEL of B-cell lineage and compare these lymphomas to HHV8-associated PEL with regard to clinical and pathological characteristics, therapy, and outcome.

\section{Introduction}

Primary effusion lymphoma (PEL) is a rare extranodal lymphoma of large B cells with characteristic clinicopathologic features including: initial presentation as a body cavity lymphomatous effusion in the absence of a detectable tumor mass; occurrence mostly in human immunodeficiency virus (HIV)-positive individuals; and expression of antigens associated with a late stage of B-cell differentiation, such as CD138 and MUM1/IRF4, without pan-B-cell antigen expression [1]. Human herpes virus-8 (HHV8), also known as Kaposi's sarcoma herpes virus (KSHV), is strongly causally related to PEL and its presence has been incorporated as a diagnostic criterion for PEL [2].

Diffuse large B-cell lymphoma (DLBCL) constitutes approximately $30-40 \%$ of all non-Hodgkin's lymphoma (NHL) and typically presents with a rapidly enlarging symptomatic mass, usually due to nodal enlargement. Extranodal disease with involvement of tissue other than lymph node, spleen, Waldeyer's ring or thymus is quite common in
DLBCL, as is secondary involvement of a body cavity by DLBCL [3]. However, primary presentation of DLBCL as a body cavity lymphomatous effusion without any detectable solid mass, similar to HHV8-associated PEL, is extremely rare. Reports of such cases of HHV8-negative PEL of Bcell lineage are limited to isolated case reports and small series. We report two additional cases of this aggressive extranodal lymphoma that presented as a solitary pleural effusion without other sites of disease at the time of diagnosis. In addition, we perform a comprehensive literature review of similar cases with the aim of further characterizing this unusual lymphoma subtype.

Case 1. An 87-year-old HIV-negative Portuguese female with a past medical history of heart failure with preserved ejection fraction $(\mathrm{EF}=60 \%)$, hypertension, atrial fibrillation, dyslipidemia, and degenerative joint disease was admitted with progressive shortness of breath of two weeks' duration. Complete blood count on admission revealed WBC count of $9600 / \mu \mathrm{L}$, hemoglobin of $13.7 \mathrm{~g} / \mathrm{dL}$, hematocrit of $42.0 \%$, 


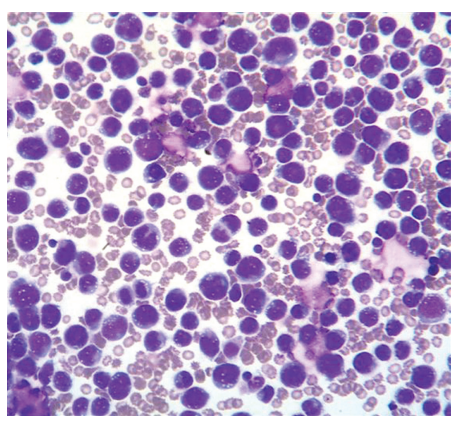

(a)

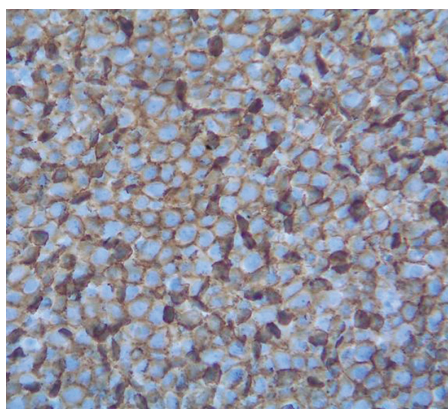

(d)

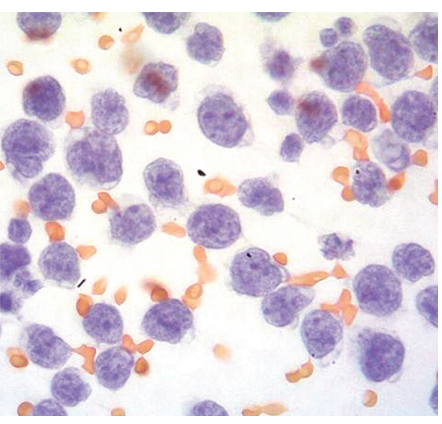

(b)

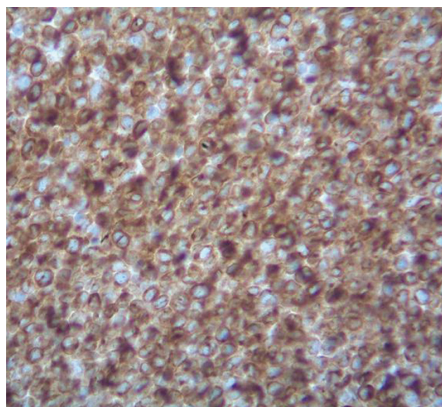

(e)

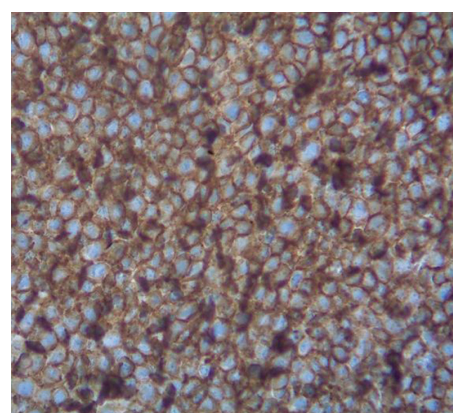

(c)

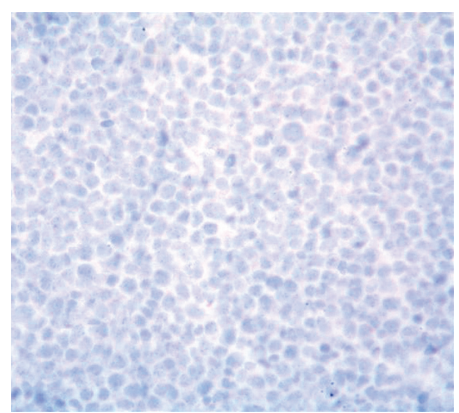

(f)

FIGURE 1: Cytological analysis revealed large atypical lymphoid cells with irregular nuclei, prominent nucleoli and basophilic vacuolated cytoplasm ((a), May-Grünwald-Giemsa; (b), Papanicolaou). By immunohistochemistry of a corresponding cell block specimen, the large cells were strongly positive for CD45 (c), CD20 (d), and CD79a (e), and were negative for CD138 (f), indicative of a mature B-cell immunophenotype.

and platelet count of $160,000 / \mu \mathrm{L}$. Serum total protein and $\mathrm{LDH}$ were $6.4 \mathrm{~g} / \mathrm{dL}$ and $184 \mathrm{IU}$, respectively. The chest X-ray showed an enlarged cardiac silhouette with bilateral pleural effusions. Thoracocentesis revealed the pleural fluid to be exudative with glucose of $3 \mathrm{mg} / \mathrm{dL}$, protein of $3.5 \mathrm{~g} / \mathrm{dL}, \mathrm{LDH}$ of $1341 \mathrm{U} / \mathrm{L}$ and 9600 nucleated cells $/ \mu \mathrm{L}$, of which 5100 were normal-appearing white blood cells (6\% neutrophils, $91 \%$ lymphocytes, 3\% monocytes) and 4500 were malignantappearing cells.

Cytocentrifuge preparation showed the malignant cells to be large lymphoid cells with irregular nuclei and deeply basophilic cytoplasm with prominent vacuoles (Figures 1(a) and 1(b)). Flow cytometry of the pleural fluid showed that the large cells were positive for CD45, CD19, CD20, CD22, CD79a, CD38, HLA-DR, and surface IgM, with aberrant expression of the T-cell antigen, CD8, and the myeloid antigen, CD13. They were negative for surface and cytoplasmic light chains, MPO, TdT and other T-cell antigens (CD2, CD3, CD4, CD7). Immunoperoxidase stains showed that neoplastic cells were positive for CD45 (Figure 1(c)), CD20 (Figure 1(d)), CD79a (Figure 1(e)), bcl-2, bcl-6 (>50\%), Ki-67 (>90\%), epithelial membrane antigen $(<50 \%)$ and negative for CD10, CD30 and CD138 (Figure 1(f)). Immunohistochemical staining for HHV8 latency associated nuclear antigen (LANA)-1 and in-situ hybridization (ISH) for Epstein-Barr virus (EBV) were negative. The patient was diagnosed with DLBCL. Further staging to exclude a primary extra-cavitary site of involvement was performed; however, no mass, organomegaly or lymphadenopathy was detected on computed tomography (CT) scans of the chest, abdomen or pelvis. Ultimately, it was felt that a diagnosis of HHV8negative PEL was most appropriate. The patient was treated only with talc pleurodesis as she declined chemotherapy and radiotherapy. She is alive approximately 24 months after the procedure and a total of 29 months after her initial presentation of bilateral pleural effusions.

Case 2. An 82-year-old HIV-negative Caucasian female with a past medical history of hypertension, sick sinus syndrome, abdominal aortic aneurysm and chronic obstructive pulmonary disease was admitted with dyspnea. Ten years earlier, she was diagnosed with non-small cell lung cancer that was treated with concurrent neoadjuvant chemotherapy and radiation followed by lobectomy. She had no interval clinical or imaging evidence of recurrence of her thoracic malignancy. Chest radiograph during the admission showed a right-sided pleural effusion. Thoracocentesis revealed malignant cells in the pleural fluid that were large lymphoid cells with irregular nuclear contours, basophilic cytoplasm and multiple nucleoli (Figures 2(a) and 2(b)). Immunohistochemical stains showed the neoplastic cells to be positive for CD20 (Figure 2(c)), PAX5/BSAP, bcl-6, MUM1/IRF4 (subset) and kappa light chain (Figure 2(d)), weakly positive for bcl-2, and negative for CD5, CD10, CD15, CD30, CD138, cyclin D1, lambda light chain (Figure 2(e)) and HHV8 LANA-1. ISH for EBVencoded RNA (EBER) was negative. Immunoglobulin heavy chain (IGH@) gene rearrangement studies showed a clonal 

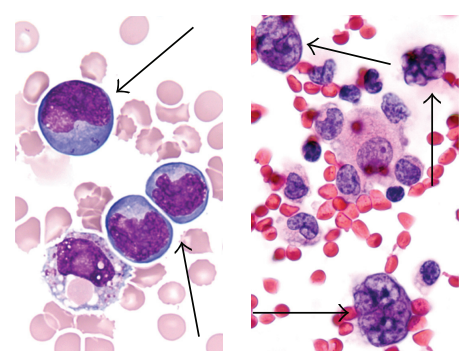

(a)

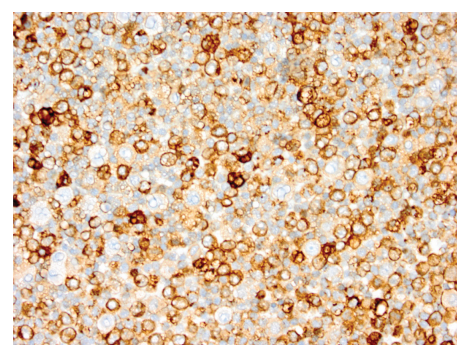

(d)

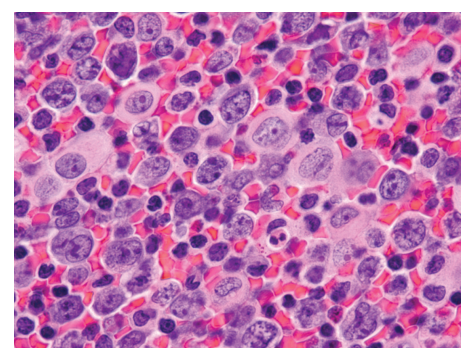

(b)

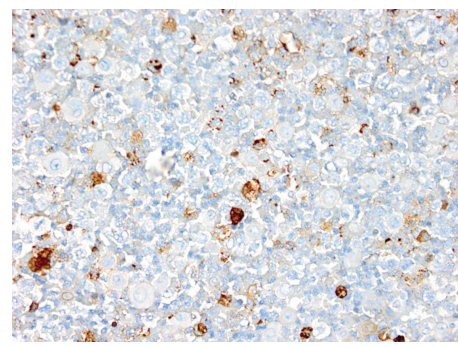

(e)

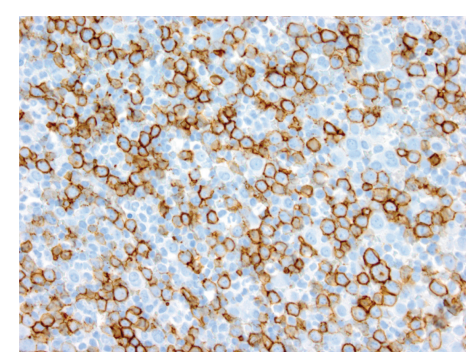

(c)

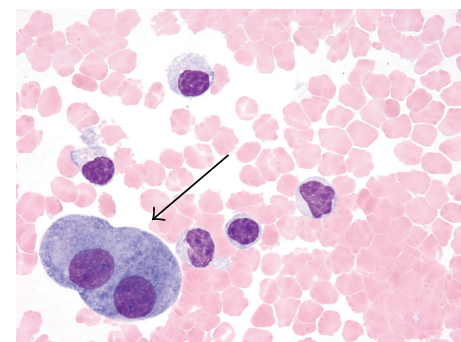

(f)

FIGURE 2: Examination of the initial thoracentesis fluid demonstrated scattered large atypical lymphoid cells with multilobated nuclei, vesicular chromatin and multiple prominent nucleoli (arrows), in a background of benign mesothelial cells, histiocytes, small lymphocytes and neutrophils ((a), left, May-Grünwald-Giemsa, and right, hematoxylin and eosin). The corresponding cell block specimen showed similar findings (hematoxylin and eosin). Immunohistochemical stains showed the scattered large cells to be positive for CD20 (c) and kappa light chain-restricted (d), with few lambda-positive cells in the background (e). A repeat thoracentesis specimen taken 1 month later showed no evidence of malignancy, with only benign mesothelial cells (arrow) and hematopoietic elements (Wright-Giemsa).

pattern [4]. F-Fluorodeoxyglucose (FDG) positron emission tomography (PET)/CT whole body scan for staging did not demonstrate additional sites of disease. The expression of mature B-cell markers and absence of HHV8, EBV, CD30 and CD138 expression excluded the diagnosis of HHV8associated PEL and the patient was given the diagnosis of HHV8-negative PEL.

The patient became symptomatic with dyspnea a month later and chest X-ray showed recurrent pleural effusion. Thoracocentesis was repeated and examination of the pleural fluid by cytology and flow cytometry revealed only reactive mesothelial cells and histiocytes, without evidence of malignant-appearing cells (Figure 2(f)). No clonal Bcell population was detected by concurrent flow cytometry. Spontaneous regression of lymphoma was re-confirmed with repeat thoracocentesis a week later yielding no malignant cells. However, follow-up FDG PET/CT whole body scans done 4 months later showed a new FDG-avid pleural-based small nodule and various nodularities in the omentum. Tissue biopsy of these nodules was not attempted, but they were believed to be consistent with metastatic progression of the lymphoma. The patient refused any chemotherapy and died 11 months after her diagnosis of lymphoma.

\section{Design and Methods}

"Primary effusion lymphoma" and "body cavity based lymphoma" were used as search terms to identify Englishlanguage articles from PubMed published in the past 15 years
(January 1997 to June 2012). Primary effusion lymphoma was defined by the presence of malignant lymphoma cells exclusively in a body cavity or cavities without any contiguous or non-contiguous tumor mass or lymph node enlargement at the time of presentation. The review was restricted to reports of primary effusion lymphomas that were negative for HHV 8 and that showed expression of mature pan-B-cell antigens. Editorials, reviews without additional cases, and non-published abstracts were excluded.

Clinical information abstracted for each case included: age at presentation; sex; HIV status by enzyme-linked immunosorbent assay (ELISA) or Western blot studies; detection of hepatitis $\mathrm{C}$ virus (HCV) by serologic studies or polymerase chain reaction (PCR); detection of EBV by PCR; site(s) of disease; therapy; and outcome. Pathological data collected for each case included: lymphoma cell morphology and immunophenotype; HHV8 LANA-1 expression by immunohistochemistry or detection of HHV8 by PCR or ISH; detection of EBV by EBV latent membrane protein-1 (LMP1) expression or EBER ISH; and results of IGH@ gene rearrangement and cytogenetic studies.

\section{Results}

The preliminary search for reports using the above mentioned terms yielded 1187 articles. After excluding reports of HHV8-associated PEL and cases of T-cell or null immunophenotype, we identified 34 articles describing 46 unique cases [4-37]. Our review includes these 46 cases and 
TABLE 1: Summary of clinical characteristics of 48 patients with HHV8-negative effusion lymphomas of B-cell lineage.

\begin{tabular}{|c|c|}
\hline Characteristics & Number of patients (\%) \\
\hline \multicolumn{2}{|l|}{ Age $(n=48)$} \\
\hline Age $>60$ & $10(20.8)$ \\
\hline Age $<60$ & $38(79.2)$ \\
\hline \multicolumn{2}{|l|}{$\operatorname{Sex}(n=48)$} \\
\hline Male & $29(60.4)$ \\
\hline Female & $19(39.6)$ \\
\hline \multicolumn{2}{|l|}{ EBV status $(n=47)$} \\
\hline Positive & $10(21.3)$ \\
\hline Negative & $37(78.7)$ \\
\hline \multicolumn{2}{|l|}{ HCV status $(n=36)$} \\
\hline Positive & $8(22.2)$ \\
\hline Negative & $28(77.8)$ \\
\hline \multicolumn{2}{|c|}{ Site $(s)$ involved $(n=41)$} \\
\hline Pleura & $27(65.9)$ \\
\hline Peritoneum & $16(39.0)$ \\
\hline Pericardium & $15(36.6)$ \\
\hline \multicolumn{2}{|l|}{ Treatment $(n=48)$} \\
\hline No chemotherapy & $17(35.42)$ \\
\hline $\mathrm{CHOP}$ & $11(22.92)$ \\
\hline $\mathrm{CHOP}+\mathrm{R}$ & $3(6.25)$ \\
\hline THP-CVP & $6(12.5)$ \\
\hline THP-CVP + R & $4(8.3)$ \\
\hline Other regimens & $6(12.5)$ \\
\hline Unknown & $1(2.0)$ \\
\hline \multicolumn{2}{|l|}{ Outcome } \\
\hline \multicolumn{2}{|c|}{ At 6 months $(n=45)$} \\
\hline Dead & (10/45) $22.2 \%$ \\
\hline Alive & (35/45) $77.8 \%$ \\
\hline \multicolumn{2}{|l|}{ At 1 year $(n=36)$} \\
\hline Dead & (14/36) 38.9\% \\
\hline Alive & $(22 / 36) 61.1 \%$ \\
\hline
\end{tabular}

Abbreviations: CHOP: cyclophosphamide, doxorubicin, vincristine, prednisone; R: Rituximab; THP-CVP-pirarubicin, cyclophosphamide, vincristine, prednisone; EBV: Epstein-Barr virus, $\mathrm{HCV}$ : hepatitis $\mathrm{C}$ virus.

our 2 cases for a total of 48 reported cases of HHV8-negative PEL.

Clinical characteristics are summarized in Table 1 and detailed clinical and pathological findings in each case are listed in Table 2 . The 48 patients had a median age at diagnosis of 74 years (range: $14-99$ years) with a male-to-female ratio of $3: 2$. Information regarding HIV status was available in 41 patients, and none were reported to be HIV-positive. The association with $\mathrm{HCV}$ and EBV infection was found to be $22.2 \%$ and $21.3 \%$, respectively. For the 41 patients with information available regarding site of disease, the frequencies of various sites of involvement were as follows: pleura: $65.9 \%$, peritoneum: $39.0 \%$, and pericardium: $36.6 \%$. A single case (case 48) involved the scrotum.

Most cases consisted of medium-sized to large or largesized cells that were occasionally described as pleomorphic.
All cases expressed one or more pan-B-cell antigens (CD19, CD20 and/or CD79a) and several cases expressed surface and/or cytoplasmic immunoglobulin, antigens typically absent in HHV8-associated PEL [16]. The immunophenotype was variable with regard to germinal center (CD10, bcl6) and post-germinal center (MUM1/IRF4) markers, but no case was reported to express CD138, a plasmacytic antigen typically seen in HHV8-associated PEL. Expression of T-cell antigens, a feature reported in occasional cases of HHV8associated PEL, was seen in only rare cases (two cases with CD5 co-expression $[22,23]$ and case 1 reported above with CD8 co-expression). At least some cytogenetic information (FISH and/or karyotype) was available in 26 cases. Of these, 12 cases showed a rearrangement or amplification involving MYC at $8 \mathrm{q} 24$ and 13 were reported to harbor a complex karyotype, although full karyotypic information was available in only a small number of cases.

Thirty patients $(62.5 \%)$ received chemotherapy with a variety of regimens, including cyclophosphamide, doxorubicin, vincristine, prednisolone (CHOP) in 11 patients; CHOP with rituximab (R) in 3 patients; THP-CVP (pirarubicin, cyclophosphamide, vincristine, prednisolone) in 6 patients; THP-CVP + R in 4 patients; and other chemotherapy regimens in 6 patients. Treatment was unknown in 1 patient. The remaining 17 patients (35.4\%) received no chemotherapy and were treated with fluid drainage alone or fluid drainage and pleurodesis. The median overall survival (OS) was 11 months. The number of patients alive at 6 months and 1 year following symptomatic presentation was $77.8 \%$ and $61.1 \%$ respectively. Patients who received no chemotherapy had a median OS of 8 months (range: 1 week to 80 months) versus 12 months (range: 18 days to 38 months) in patients who received any kind of chemotherapy. The rate of death with any kind of chemotherapy at 6 months was $20 \%$ and at 1 year was $33 \%$, compared to $25 \%$ and $42 \%$ without any chemotherapy. Among the 22 patients who died of their lymphoma, the median OS was 7 months (range: 1 week to 80 months). The median follow-up period in 24 living patients was approximately 14.5 months (range: 2 months to 55 months).

\section{Discussion}

Body cavity-based lymphomas are a heterogeneous group of rare non-Hodgkin's lymphomas that arise primarily in the serous body cavities and that result in recurrent effusions. This group includes pyothorax-associated lymphoma and PEL. Pyothorax-associated lymphoma presents as a solid mass localized in the thoracic cavity that is contiguous with the effusion; it is EBV-associated and arises in the setting of long-standing pyothorax resulting from iatrogenic pneumothorax used to treat tuberculosis [38]. In contrast, PEL is typically confined to a body cavity and grows in a liquid phase, without any detectable nodal or extranodal mass elsewhere in the body. As illustrated in Figure 3, PEL can be broadly divided into two categories: HHV8-associated PEL, a subtype of DLBCL and a distinct category in the 2008 WHO Classification of Neoplasms of Haematopoietic and Lymphoid 


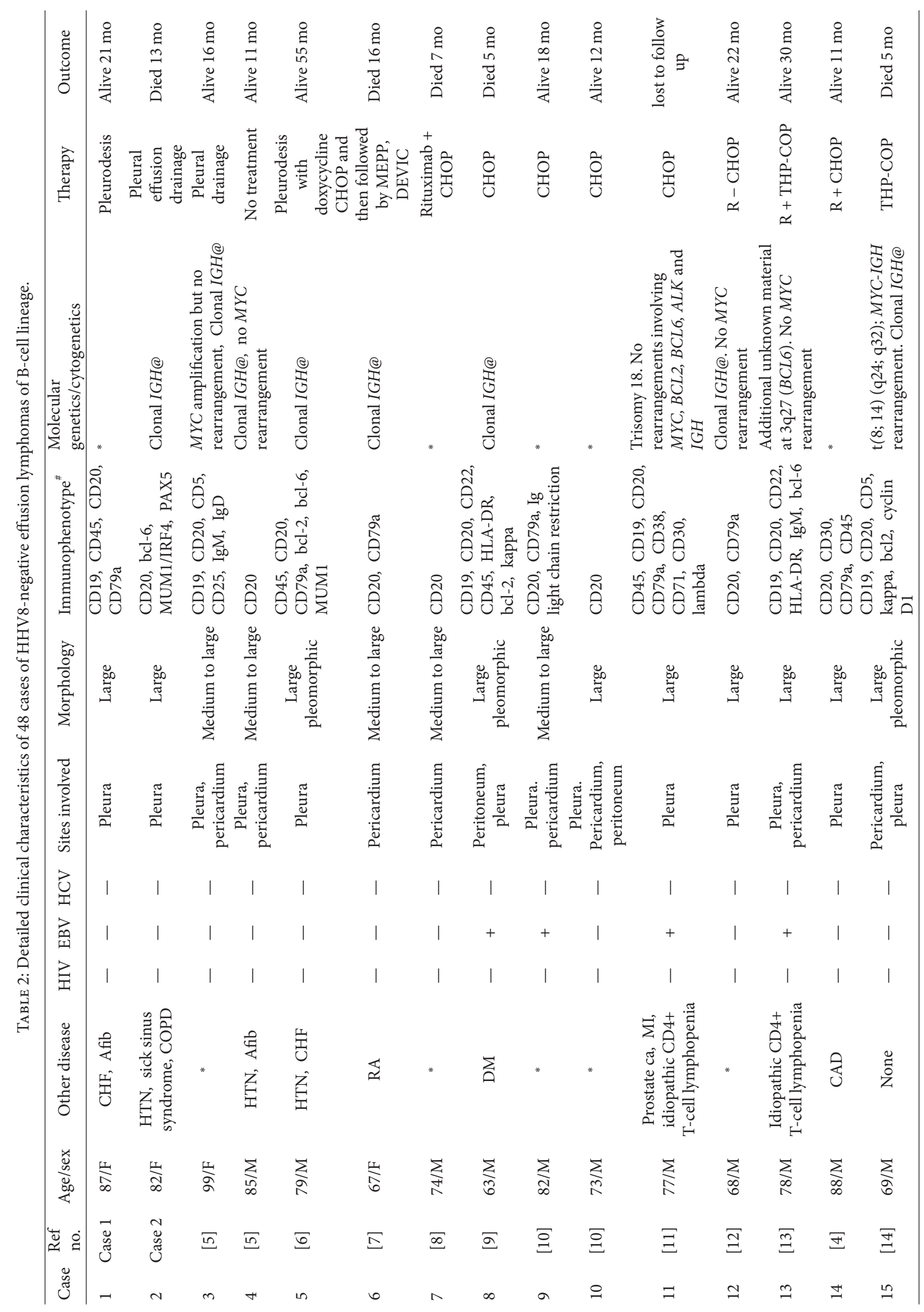




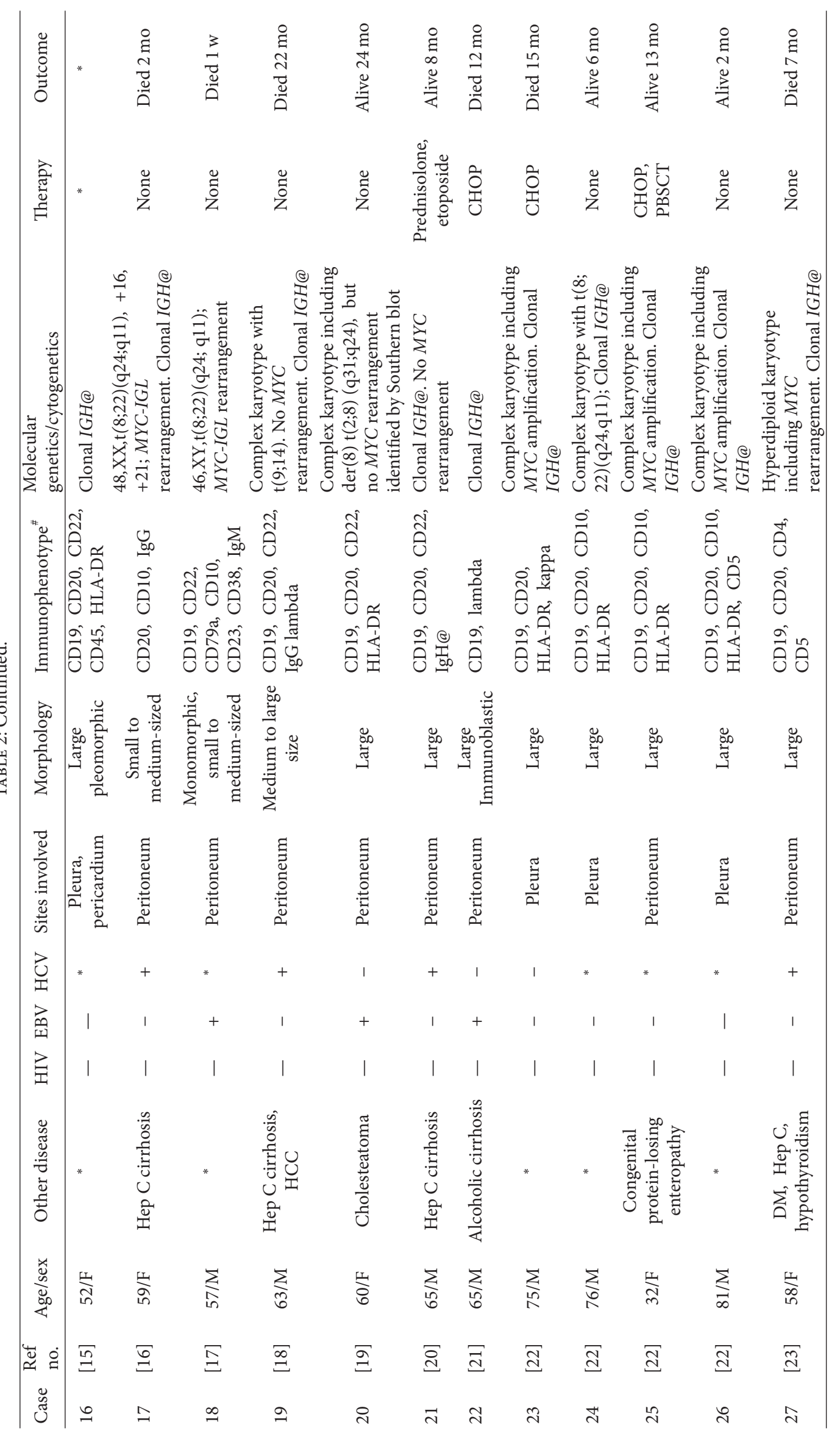




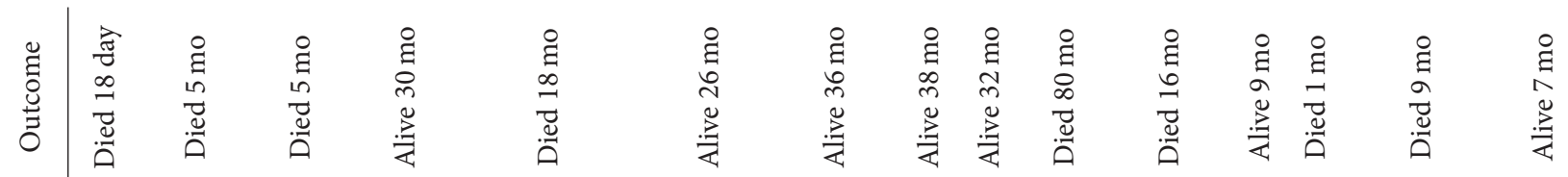

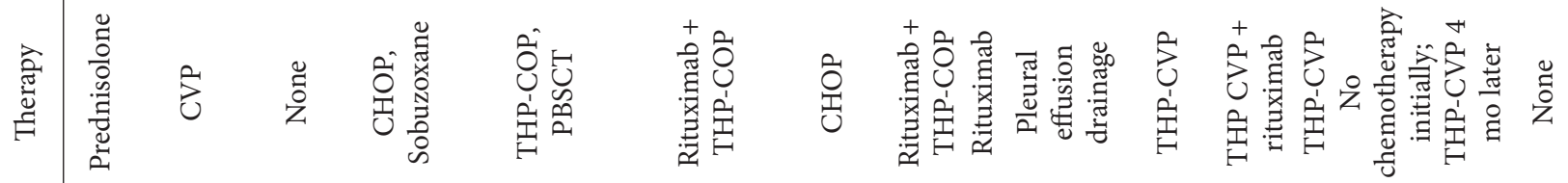

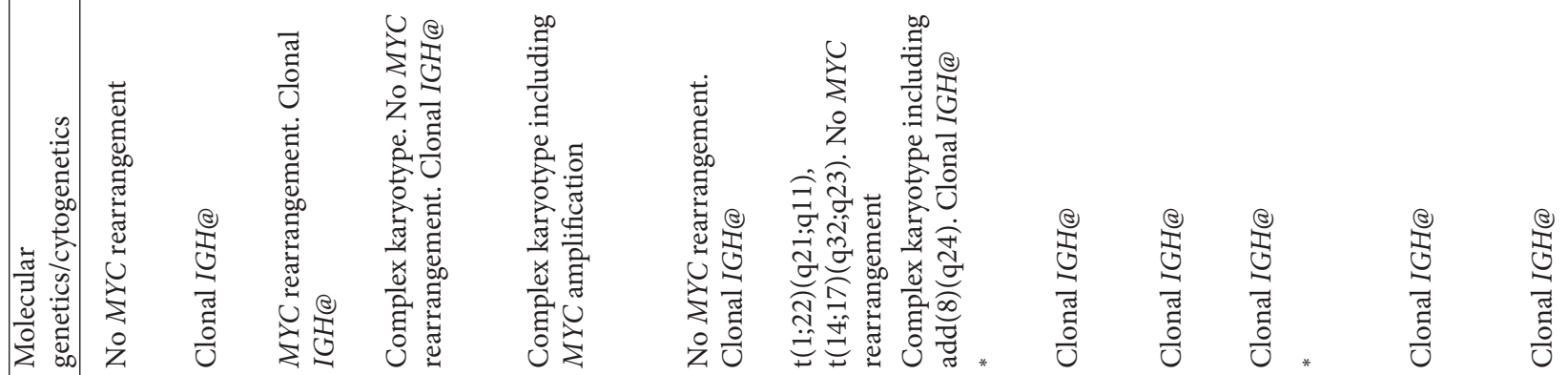

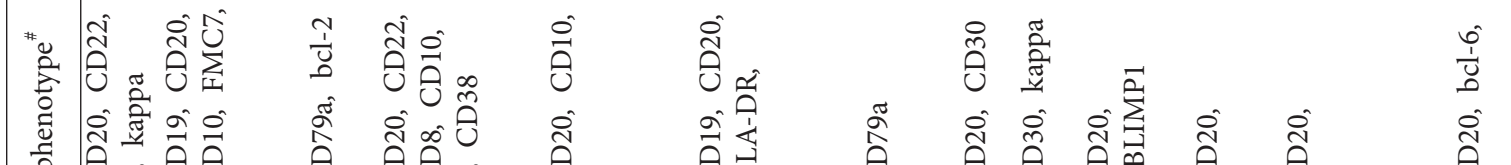

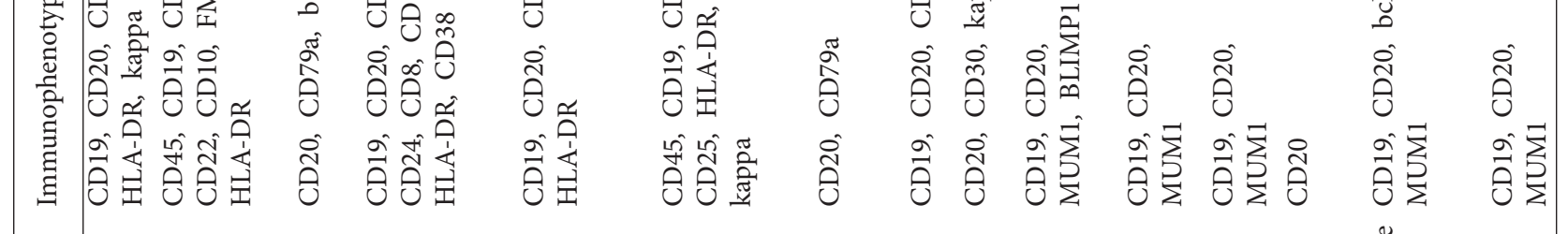

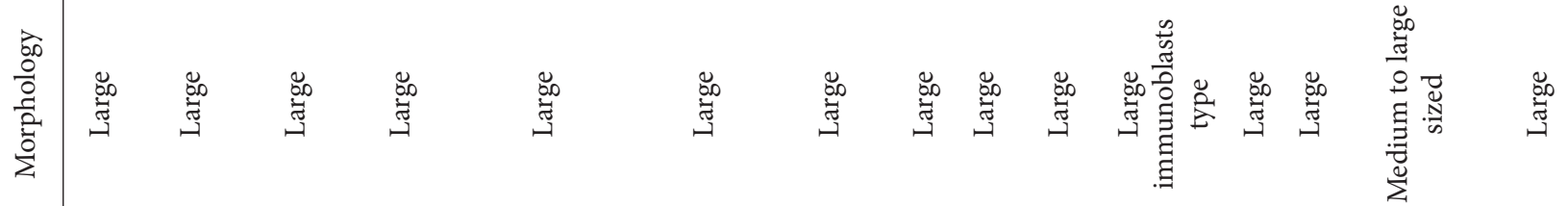

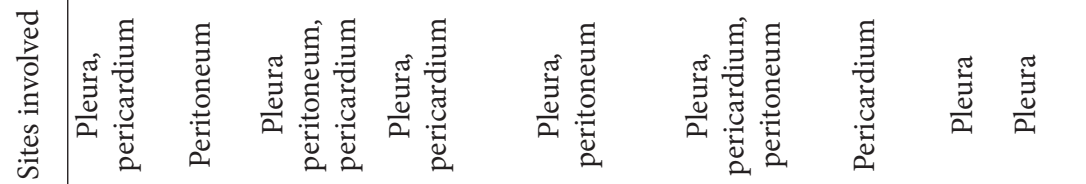

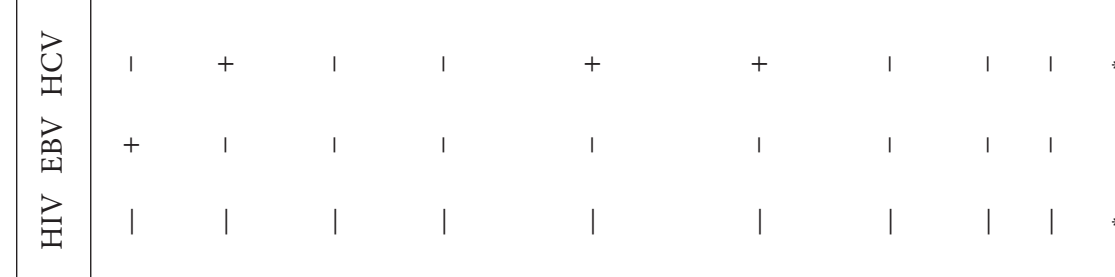

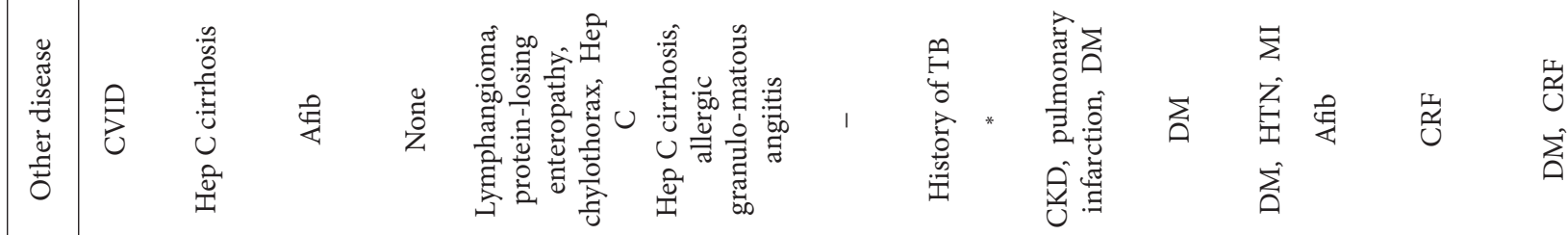
离

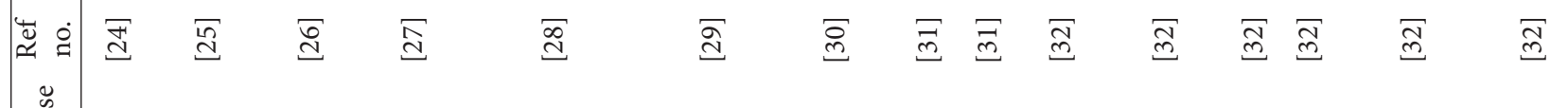

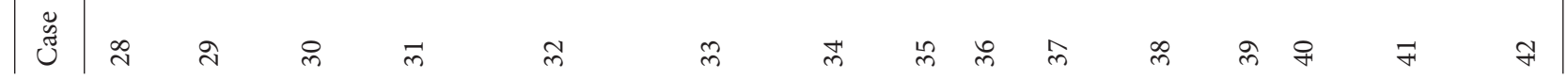




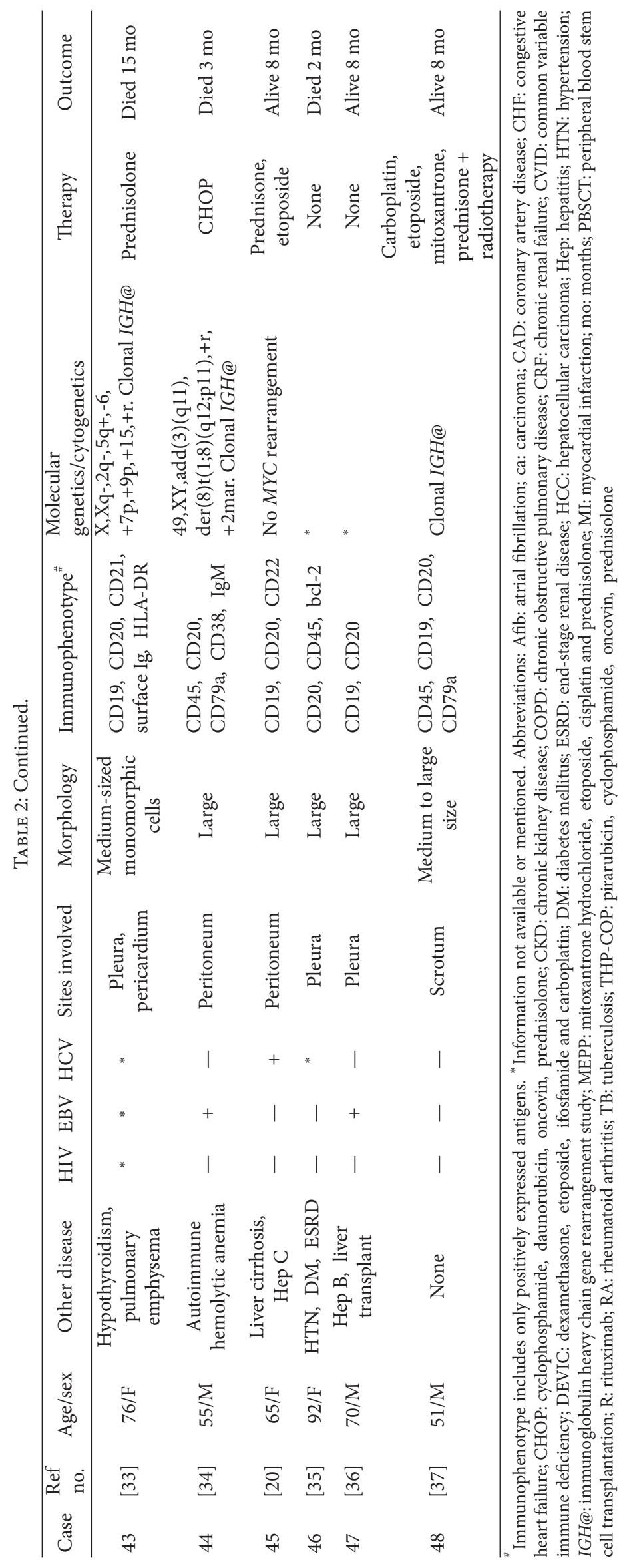




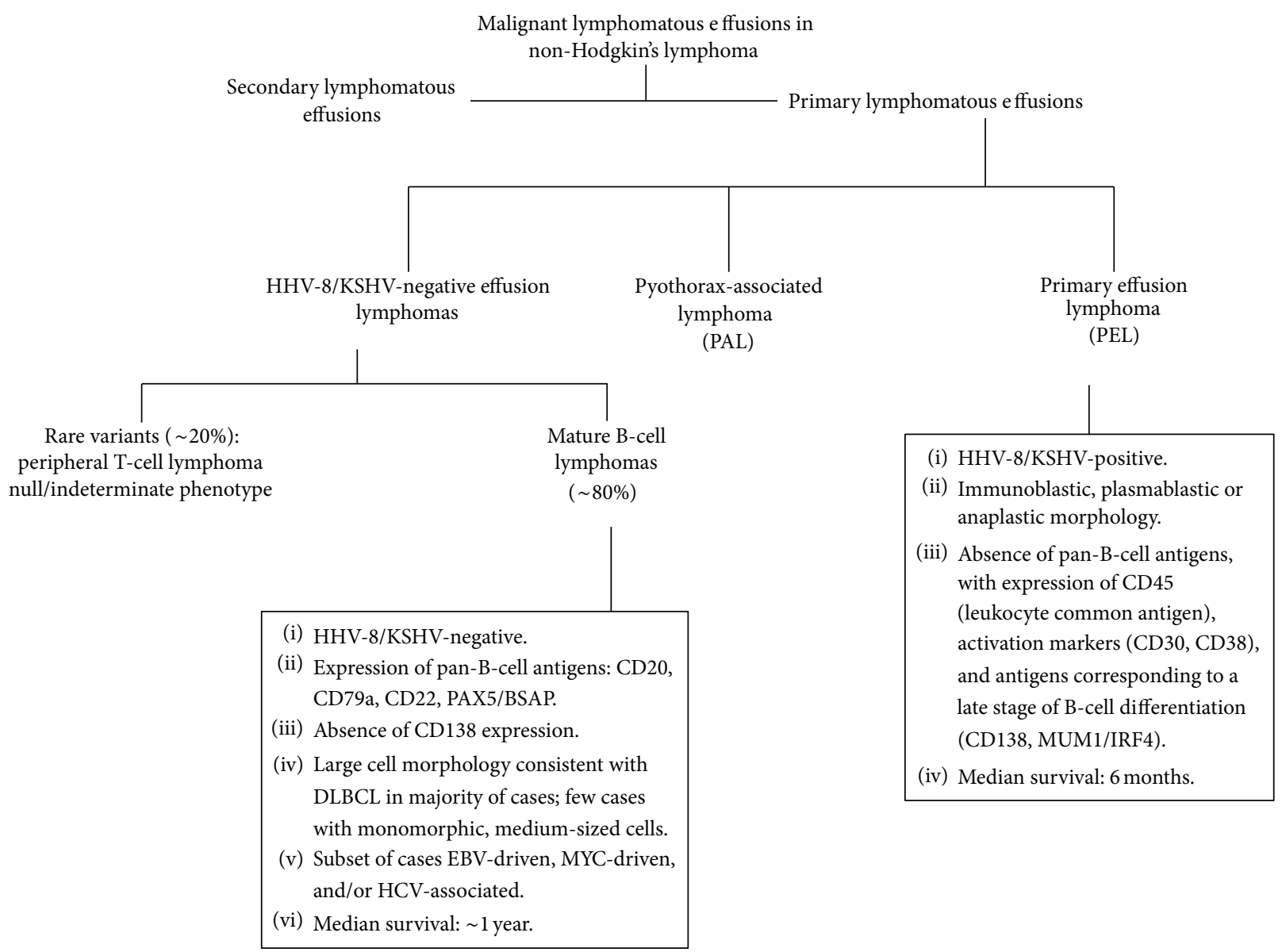

Figure 3: A schema of malignant lymphomatous effusions in non-Hodgkin's lymphoma highlighting the differences between HHV8associated PEL and HHV8-negative PEL.

Tissues [2], and HHV8-negative PEL, of which the majority ( $\sim 80 \%$ of cases) express mature pan-B-cell antigens [39]. As only rare cases of HHV8-negative PEL with neoplastic cells of T-cell derivation [40-44] or null/indeterminate immunophenotype $[22,45,46]$ have been reported, we restricted our review to $\mathrm{HHV} 8$-negative $\mathrm{PEL}$ of $\mathrm{B}$-cell lineage. Our report of two cases and review of the literature demonstrates that these neoplasms are heterogenous, but share common features that distinguish them from HHV8-associated PEL with regard to pathogenesis, clinical characteristics, immunophenotype and prognosis.

While none of the 48 patients with HHV8-negative PEL were HIV-positive, EBV infection was seen in $21.3 \%$ of cases, suggesting that altered immunosurveillance may play a pathogenetic role in some cases. Among the $10 \mathrm{EBV}-$ positive cases, all patients were $>50$ years old, 2 patients had idiopathic CD4+ T-cell lymphopenia and 1 patient had a history of common variable immunodeficiency, supporting this hypothesis [47]. Similarly, $22.2 \%$ of patients had underlying $\mathrm{HCV}$ infection. $\mathrm{HCV}$ has been shown to be lymphotropic and has been implicated as an etiological factor in lymphomagenesis for various NHL subtypes [48, 49].
Ascoli et al. detected HCV RNA in the ascitic fluid of a patient with HHV8-negative PEL and proposed that HCV may play a causative role in these lymphomas by chronic stimulation of B cells followed by clonal expansion [16].

In our review, a number of cases were negative for both EBV and HCV (19/48; 39.6\%), suggesting that other etiologies also play a role in lymphomagenesis. Among cases with available cytogenetic information, 50\% (12/26) harbored amplification or rearrangement of the MYC oncogene, a likely driver of neoplasia in these cases. In terms of Bcell NHL subclassification, most MYC-rearranged cases had large cell morphology or a complex karyotype, consistent with DLBCL $[14,19,22,23,26,31,50]$ Two cases (cases 17 and 18) reportedly had monomorphic medium-sized cells, a germinal center immunophenotype (expression of CD10), and a relatively simple background karyotype, suggesting that these cases may represent an unusual extranodal presentation of Burkitt's lymphoma [16, 17].

Unlike HHV8-associated PEL, HHV8-negative PEL of B-cell lineage shares several clinical features with nodal or extranodal DLBCL presenting with a mass lesion, and differentiating HHV8-negative PEL from conventional DLBCL 
complicated by secondary lymphomatous effusion requires a thorough staging evaluation to exclude the presence of a mass lesion at the time of diagnosis. Based on our literature review, HHV8-negative PEL presents at an older median age (74 years) compared to that reported for $\mathrm{HHV} 8$-associated PEL (44 years) and exhibits a lower male-to-female ratio, similar to DLBCL [2, 44, 51, 52]. The overall favorable prognosis compared to HHV8-associated PEL was underscored by a survival rate of approximately $60 \%$ at 1 year and a median OS of 11 months. While this compares favorably to HHV8associated PEL with a reported median OS of 4-6 months $[2,44]$, the range was quite wide (1 week to 80 months). This heterogeneity in clinical behavior is further highlighted by our finding of a small number of patients who presented with involvement limited to a single body cavity site, but who developed mass lesions outside of the body cavity at the time of disease progression, similar to our case 2 [32]. At the other extreme, our case 1 showed regression of the malignancy after pleurodesis and drainage of the pleural fluid without any chemotherapy, and in our literature review we identified 7 other patients in whom the lymphoma similarly regressed following drainage of the effusion [5-7, 12, 18, 23].

There is no clear consensus on the appropriate treatment of HHV8-negative PEL due to the limited number of cases reported. Our findings suggest that chemotherapy benefits most patients, as those treated with any type of chemotherapy overall had a lower rate of death compared to patients who received no chemotherapy. Remarkably, the addition of rituximab to chemotherapy regimens induced remission in all 8 patients, 7 of whom were alive at the time of last follow-up $[4,8,12,13,29,31,32]$. The single patient who died following a rituximab-containing regimen died prematurely of a cause unrelated to lymphoma [8]. Therefore, treatment with drainage of the effusion followed by chemoimmunotherapy with rituximab and $\mathrm{CHOP}$, particularly in CD20-positive cases, appears to offer the possibility of prolonged survival in a subset of patients. Further study of rare patients who undergo spontaneous regression of their lymphoma following drainage alone may help to identify clinical or pathological features that predict for a good outcome following only minimal therapy.

\section{Acknowledgments}

All authors acknowledge no financial interests or motives in contribution of the manuscript.

\section{Authors' Contributions}

Each author has participated sufficiently in the work to take public responsibility for the content.

\section{References}

[1] A. Carbone and A. Gloghini, "PEL and HHV8-unrelated effusion lymphomas: classification and diagnosis," Cancer, vol. 114, no. 4, pp. 225-227, 2008.

[2] J. Said, E. Cesarman, and N. L. Harris, "Primary effusion lymphoma," in WHO Classification of Tumours of Haematopoietic and Lymphoid Tissues, S. H. Swerdlow, Ed., pp. 260-261, IARC Press, Lyon, France, 4th edition, 2008.

[3] M. B. Møller, N. T. Pedersen, and B. E. Christensen, "Diffuse large B-cell lymphoma: clinical implications of extranodal versus nodal presentation-a population-based study of 1575 cases," British Journal of Haematology, vol. 124, no. 2, pp. 151-159, 2004.

[4] I. Youngster, E. Vaisben, H. Cohen, and F. Nassar, "An unusual cause of pleural effusion," Age and Ageing, vol. 35, no. 1, pp. 94-96, 2006.

[5] Y. Terasaki, H. Yamamoto, H. Kiyokawa et al., "Disappearance of malignant cells by effusion drainage alone in two patients with HHV-8-unrelated HIV-negative primary effusion lymphoma-like lymphoma," International Journal of Hematology, vol. 94, pp. 279-284, 2011.

[6] T. Wang, V. E. Nava, G. P. Schechter, and J. H. Lichy, "Human herpes virus 8-unrelated primary effusion lymphoma-like lymphoma: a patient successfully treated with pleurodesis," Journal of Clinical Oncology, vol. 29, pp. e747-e750, 2011.

[7] S. Inoue, T. Miyamoto, T. Yoshino, I. Yamadori, Y. Hagari, and O. Yamamoto, "Primary effusion lymphoma with skin involvement," Journal of Clinical Pathology, vol. 59, no. 11, pp. 1221-1222, 2006.

[8] Y. Kagoya, T. Takahashi, T. Yoshimoto et al., "Recurrent pericardial effusion after treatment for primary effusion lymphomalike lymphoma: an autopsied case," Annals of Hematology, vol. 90, no. 2, pp. 219-220, 2011.

[9] F. Ceran, Y. Aydin, L. Özçakar, U. Han, and M. Yildiz, "Primary effusion lymphoma: an untrivial differential diagnosis for ascites," Yonsei Medical Journal, vol. 50, no. 6, pp. 862-864, 2009.

[10] T. Takahashi, A. Hangaishi, G. Yamamoto, M. Ichikawa, Y. Imai, and M. Kurokawa, "HIV-negative, HHV-8-unrelated primary effusion lymphoma-like lymphoma: report of two cases," American Journal of Hematology, vol. 85, no. 1, pp. 85-87, 2010.

[11] N. J. Tsagarakis, A. Argyrou, G. Gortzolidis et al., "Report of an HIV and HHV-8 negative case of primary effusion lymphoma with idiopathic T4 lymphocytopenia," International Journal of Hematology, vol. 90, no. 1, pp. 94-98, 2009.

[12] Y. Terasaki, H. Okumura, K. Saito et al., "HHV-8/KSHVnegative and CD20-positive primary effusion lymphoma successfully treated by pleural drainage followed by chemotherapy containing rituximab," Internal Medicine, vol. 47, no. 24, pp. 2175-2178, 2008.

[13] D. Niino, K. Tsukasaki, K. Torii et al., "Human herpes virus 8negative primary effusion lymphoma with BCL6 rearrangement in a patient with idiopathic CD4 positive T-lymphocytopenia," Haematologica, vol. 93, no. 1, pp. e21-e23, 2008.

[14] S. Fujisawa, F. Tanioka, T. Matsuoka, and T. Ozawa, "CD5+ diffuse large B-cell lymphoma with c-myc/IgH rearrangement presenting as primary effusion lymphoma," International Journal of Hematology, vol. 81, no. 4, pp. 315-318, 2005.

[15] O. Hermine, M. Michel, A. Buzyn-Veil et al., "Body-cavitybased lymphoma in an HIV-seronegative patient without Kaposi's sarcoma-associated herpesvirus-like DNA sequences," New England Journal of Medicine, vol. 334, no. 4, pp. 272-273, 1996.

[16] V. Ascoli, F. Lo Coco, M. Artini, M. Levrero, A. Fruscalzo, and C. Mecucci, "Primary effusion Burkitt's lymphoma with $t(8 ; 22)$ in a patient with hepatitis C virus related cirrhosis," Human Pathology, vol. 28, no. 1, pp. 101-104, 1997.

[17] A. Carbone, "Establishment of HHV-8-positive and HHV-8negative lymphoma cell lines from primary lymphomatous 
effusions," International Journal of Cancer, vol. 73, pp. 562-569, 1997.

[18] R. Ichinohasama, I. Miura, N. Kobayashi et al., "Herpes virus type 8-negative primary effusion lymphoma associated with PAX-5 gene rearrangement and hepatitis C virus," American Journal of Surgical Pathology, vol. 22, no. 12, pp. 1528-1537, 1998.

[19] E. Ashihara, C. Shimazaki, H. Hirai et al., "Human herpes virus 8-negative primary effusion lymphoma in a patient with a ventriculoperitoneal shunt tube," International Journal of Hematology, vol. 74, no. 3, pp. 327-332, 2001.

[20] T. Hara, S. Nishi, A. Horimoto, S. Takenaka, Y. Ibata, and H. Akamatsu, "Primary effusion lymphoma in a patient with hepatitis C virus-related liver cirrhosis," Journal of Gastroenterology and Hepatology, vol. 16, no. 8, pp. 948-949, 2001.

[21] J. Rodriguez, J. E. Romaguera, R. L. Katz, J. Said, and F. Cabanillas, "Primary effusion lymphoma in an Hiv-negative patient with no with no serologic evidence of Kaposi's sarcoma virus," Leukemia and Lymphoma, vol. 41, no. 1-2, pp. 185-189, 2001.

[22] K. Ohshima, M. Ishiguro, S. Yamasaki et al., "Chromosomal and comparative genomic analyses of HHV-8-negative primary effusion lymphoma in five HIV-negative Japanese patients," Leukemia and Lymphoma, vol. 43, no. 3, pp. 595-601, 2002.

[23] M. Saiki, T. Saitoh, M. Inoue et al., "Human herpesvirus-8 negative primary effusion lymphoma with complete clinical remission after removal of ascites," The Japanese Journal of Clinical Hematology, vol. 43, no. 7, pp. 548-553, 2002.

[24] A. Hisamoto, H. Yamane, A. Hiraki et al., "Human herpes virus8-negative primary effusion lymphoma in a patient with common variable immunodeficiency," Leukemia and Lymphoma, vol. 44, no. 11, pp. 2019-2022, 2003.

[25] G. P. Paner, J. Jensen, K. E. Foreman, and C. V. Reyes, "HIV and HHV-8 negative primary effusion lymphoma in a patient with hepatitis C virus-related liver cirrhosis," Leukemia and Lymphoma, vol. 44, no. 10, pp. 1811-1814, 2003.

[26] M. Shimazaki, M. Fujita, K. Tsukamoto et al., "An unusual case of primary effusion lymphoma in a HIV-negative patient not pathogenetically associated with HHV8," European Journal of Haematology, vol. 71, no. 1, pp. 62-67, 2003.

[27] Y. Inoue, K. Tsukasaki, K. Nagai, H. Soda, and M. Tomonaga, "Durable remission by sobuzoxane in an HIV-seronegative patient with human herpesvirus 8-negative primary effusion lymphoma," International Journal of Hematology, vol. 79, no. 3, pp. 271-275, 2004.

[28] A. Nonami, T. Yokoyama, M. Takeshita, K. Ohshima, A. Kubota, and S. Okamura, "Human herpes virus 8-negative primary effusion lymphoma (PEL) in a patient after repeated chylous ascites and chylothorax," Internal Medicine, vol. 43, no. 3, pp. 236-242, 2004.

[29] T. Takao, Y. Kobayashi, J. Kuroda et al., "Rituximab is effective for human herpesvirus-8-negative primary effusion lymphoma with CD20 phenotype associated hepatitis $C$ virus-related liver cirrhosis," American Journal of Hematology, vol. 77, no. 4, pp. 419-420, 2004.

[30] T. Fujiwara, R. Ichinohasama, I. Miura et al., "Primary effusion lymphoma of the pericardial cavity carrying $\mathrm{t}(1 ; 22)(\mathrm{q} 21 ; \mathrm{q} 11)$ and t(14;17)(q32;q23)," Cancer Genetics and Cytogenetics, vol. 156, no. 1, pp. 49-53, 2005.

[31] Y. Matsumoto, K. Nomura, K. Ueda et al., "Human herpesvirus 8-negative malignant effusion lymphoma: a distinct clinical entity and successful treatment with rituximab," Leukemia and Lymphoma, vol. 46, no. 3, pp. 415-419, 2005.

[32] K. Kishimoto, T. Kitamura, Y. Hirayama, G. Tate, and T. Mitsuya, "Cytologic and immunocytochemical features of EBV negative primary effusion lymphoma: report on seven Japanese cases," Diagnostic Cytopathology, vol. 37, no. 4, pp. 293-298, 2009.

[33] M. Iwahashi, S. Iida, S. Sako et al., "Primary effusion lymphoma with B-cell phenotype," American Journal of Hematology, vol. 64, pp. 317-318, 2000.

[34] H. Chiba, T. Matsunaga, K. Kuribayashi et al., "Autoimmune hemolytic anemia as a first manifestation of primary effusion lymphoma," Annals of Hematology, vol. 82, no. 12, pp. 773-776, 2003.

[35] S. Nemr, M. H. Mayor-Modesto, S. Schwartz, and E. M. Summerhill, "A 92-year-old woman with recurrent pleural effusions," Chest, vol. 134, no. 1, pp. 196-199, 2008.

[36] N. P. Ohori, R. E. Whisnant, M. A. Nalesnik, and S. H. Swerdlow, "Primary pleural effusion posttransplant lymphoproliferative disorder: distinction from secondary involvement and effusion lymphoma," Diagnostic Cytopathology, vol. 25, no. 1, pp. 50-53, 2001.

[37] Y. Nakamura, F. Tajima, H. Omura et al., "Primary effusion lymphoma of the left scrotum," Internal Medicine, vol. 42, pp. 351-353, 2003.

[38] S. Nakatsuka, M. Yao, Y. Hoshida et al., "Pyothorax-associated lymphoma: a review of 106 cases," Journal of Clinical Oncology, vol. 20, pp. 4260-4255, 2002.

[39] C. Adiguzel, S. U. Bozkurt, I. Kaygusuz et al., "Human herpes virus 8-unrelated primary effusion lymphoma-like lymphoma: report of a rare case and review of the literature," Acta Pathologica, Microbiologica, et Immunologica Scandinavica, vol. 117, pp. 222-29, 2009.

[40] I. Venizelos, D. Tamiolakis, M. Lambropoulou et al., "An unusual case of posttransplant peritoneal primary effusion lymphoma with T-cell phenotype in a HIV-negative female, not associated with HHV-8," Pathology and Oncology Research, vol. 11, no. 3, pp. 178-181, 2005.

[41] A. C. L. Chan, J. K. C. Chan, K. W. Yan, and Y. L. Kwong, "Anaplastic large cell lymphoma presenting as a pleural effusion and mimicking primary effusion lymphoma: a report of 2 cases," Acta Cytologica, vol. 47, no. 5, pp. 809-816, 2003.

[42] Y. Yamamoto, H. Kitajima, H. Sakihana, T. Shigeki, and S. Fukuhara, "T-cell lymphoma with clinical features of primary effusion lymphoma: an autopsy case," International Journal of Hematology, vol. 74, no. 4, pp. 442-446, 2001.

[43] H. Yasuda, M. Nakao, H. Kanemasa et al., "T-cell lymphoma presenting with pericardial and pleural effusion as the initial and primary lesion: cytogenetic and molecular evidence," Internal Medicine, vol. 35, no. 2, pp. 150-154, 1996.

[44] Y. Kobayashi, Y. Kamitsuji, J. Kuroda et al., "Comparison of human herpes virus 8 related primary effusion lymphoma with human herpes virus 8 unrelated primary effusion lymphomalike lymphoma on the basis of HIV: report of 2 cases and review of 212 cases in the literature," Acta Haematologica, vol. 117, no. 3, pp. 132-144, 2007.

[45] S. Tanaka, H. Katano, K. Tsukamoto et al., "HHV8-negative primary effusion lymphoma of the peritoneal cavity presenting with a distinct immunohistochemical phenotype," Pathology International, vol. 51, no. 4, pp. 293-300, 2001.

[46] A. Carbone, A. Gloghini, E. Vaccher et al., "Kaposi's sarcomaassociated herpesvirus DNA sequences in AIDS-related and 
AIDS-unrelated lymphomatous effusions," British Journal of Haematology, vol. 94, no. 3, pp. 533-543, 1996.

[47] S. Nakamura, E. Jaffe, and S. Swerdlow, "EBV positive diffuse large B-cell of the elderly," in WHO Classification of Tumours of Haematopoietic and Lymphoid Tissues, S. Swerdlow, Ed., pp. 243-244, IARC Press, Lyon, France, 2008.

[48] S. De Vita, D. Sansonno, R. Dolcetti et al., "Hepatitis C virus within a malignant lymphoma lesion in the course of type II mixed cryoglobulinemia," Blood, vol. 86, no. 5, pp. 1887-1892, 1995.

[49] F. Franzin, D. G. Efremov, G. Pozzato, P. Tulissi, F. Batista, and O. R. Burrone, "Clonal B-cell expansions in peripheral blood of HCV-infected patients," British Journal of Haematology, vol. 90, no. 3, pp. 548-552, 1995.

[50] A. R. Sohani and R. P. Hasserjian, "Diagnosis of Burkitt lymphoma and related high-grade B-cell neoplasms," Surgical Pathology Clinics, vol. 3, no. 4, pp. 1035-1059, 2010.

[51] J. A. Ferry, "Lymphomas of the thorax," in Extranodal Lymphomas, J. A. Ferry, Ed., pp. 93-96, Elsevier, Philadelphia, Pa, USA, 2nd edition, 2011.

[52] H. Stein, R. A. Warnke, W. C. Chan et al., "Diffuse large Bcell lymphoma, not otherwise specified," in WHO Classification of Tumours of Haematopoietic and Lymphoid Tissues, S. H. Swerdlow, E. Campo, N. L. Harris et al., Eds., pp. 233-237, IARC Press, Lyon, France, 2008. 


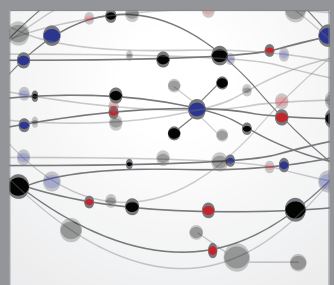

The Scientific World Journal
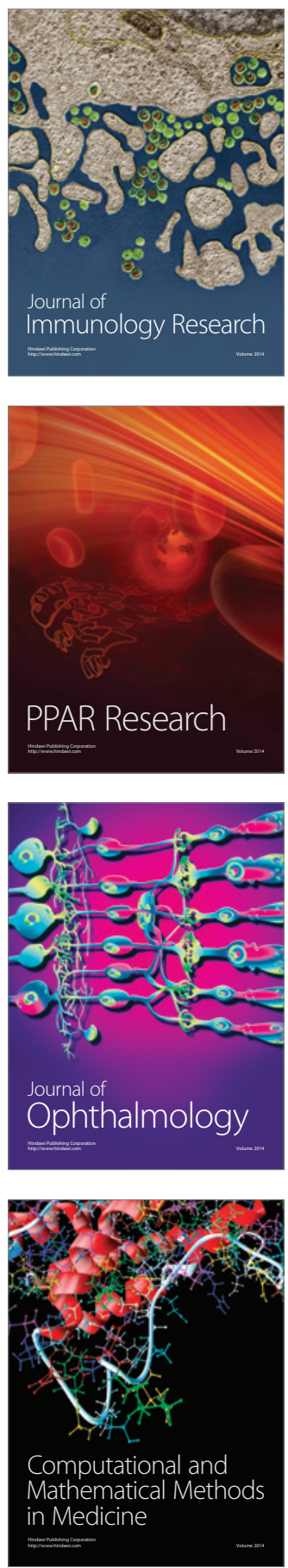

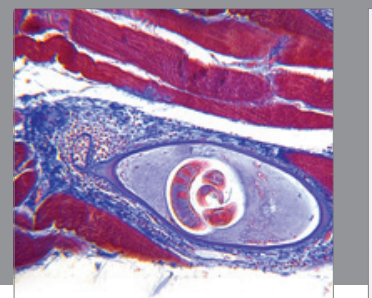

Gastroenterology

Research and Practice
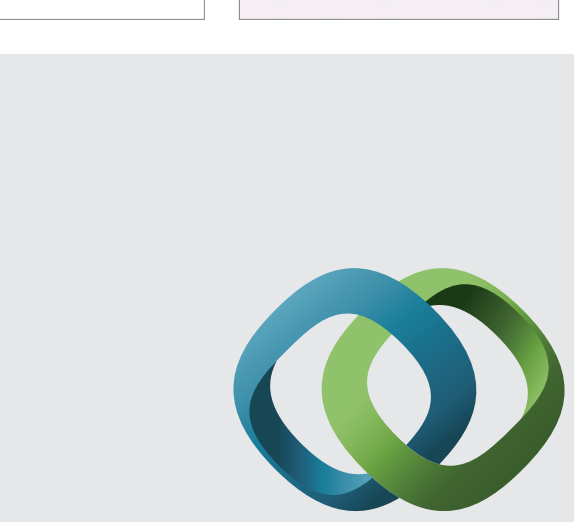

\section{Hindawi}

Submit your manuscripts at

http://www.hindawi.com
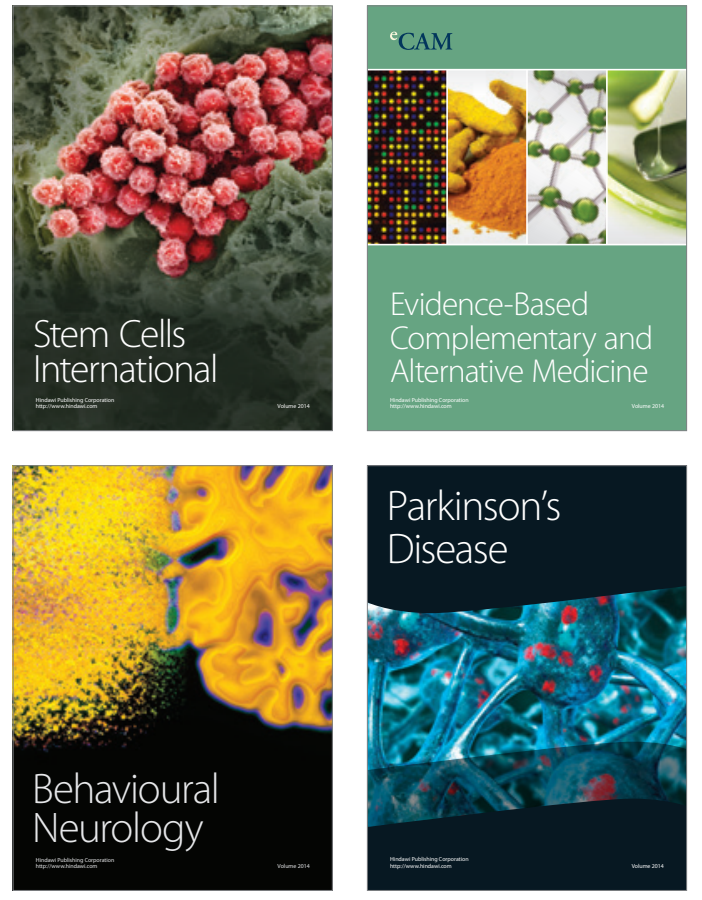
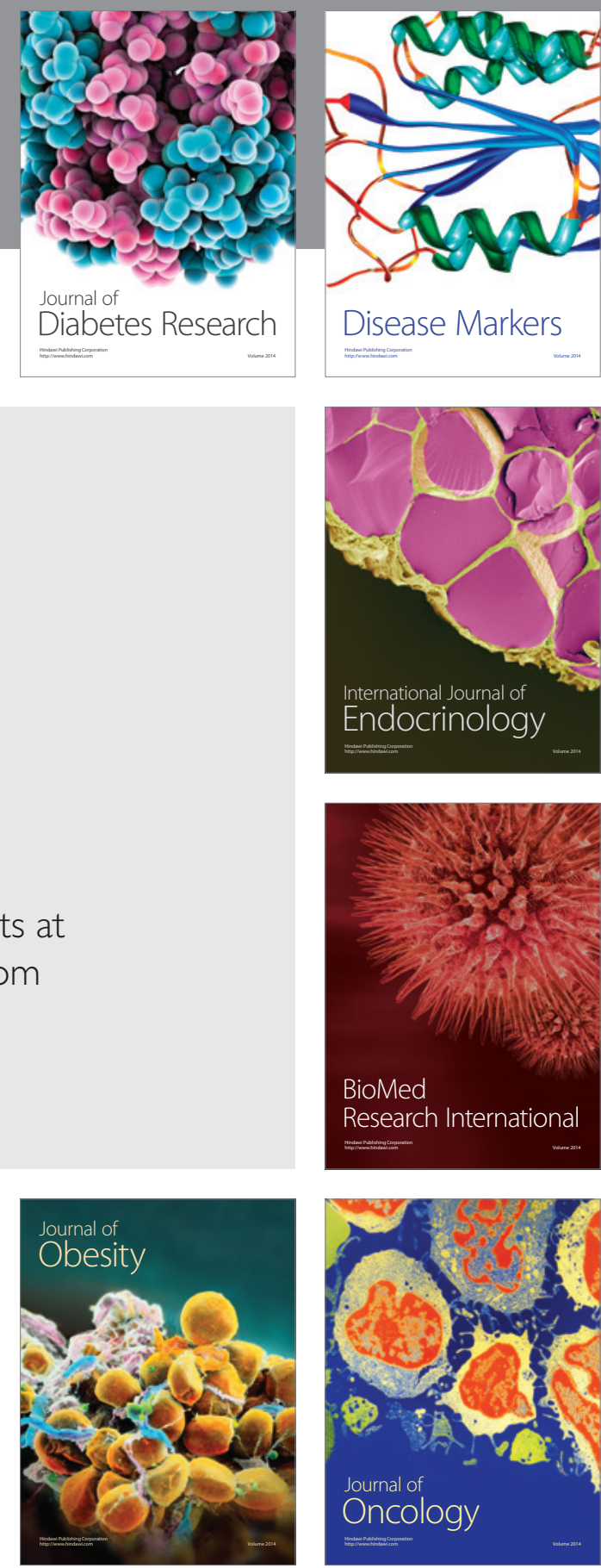

Disease Markers
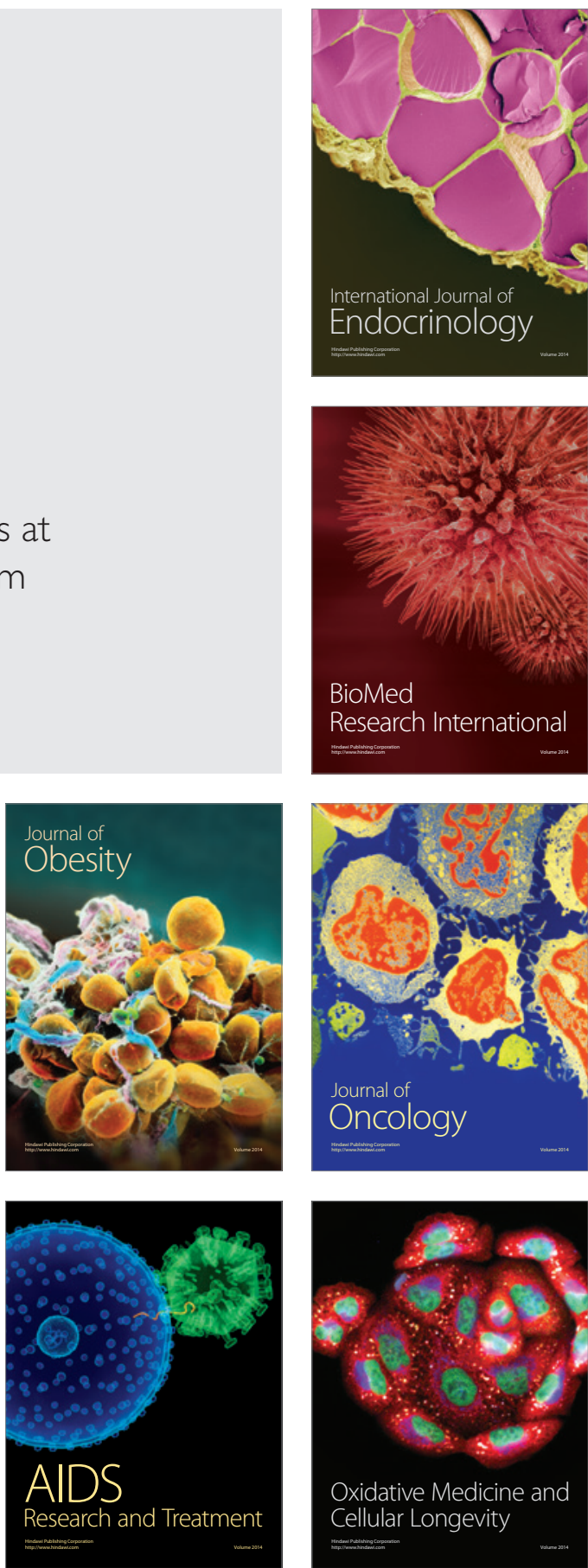